\title{
¿QUIÉN ESTÁ A CARGO DE LA GESTIÓN DE LA EDUCACIÓN PÚBLICA ESCOLAR? \\ UN ANÁLISIS DE LA REGULACIÓN LEGAL DE LAS ESCUELAS "MUNICIPALES"*
}

\section{Lucas Mac-Clure}

\begin{abstract}
La regulación jurídica de la gestión escolar en Chile suele entenderse como portadora de la "municipalización" de la educación pública. En este trabajo se sostiene que un análisis de la regulación legal de las escuelas municipales contenida en el Estatuto Docente y en otras leyes indica que ésa es una interpretación errada. Contrariamente a lo que se supone, la regulación que ha regido hasta ahora establece una difusión de competencias de decisión y, por tanto, de responsabilidades entre varios agentes públicos y privados. $\mathrm{Y}$ en varios aspectos que algunos considerarían claves, como nombramientos y remoción de profesores y directores, y estructura de remuneraciones, la regulación simplemente pone múlti-
\end{abstract}

LuCAS Mac-Clure. Abogado, Universidad de Chile. Actualmente realiza estudios de posgrado en derecho, en la Universidad de Yale.

* Versión revisada del trabajo presentado en seminario realizado en el CEP el 25 de mayo de 2010 e incluido luego en la serie Puntos de Referencia No 322 (junio 2010), Centro de Estudios Públicos.

Agradezco a Harald Beyer, Alejandro Donoso, Arturo Fontaine, Verónica Monsalve, Jorge Pavez, Carmen Luz Salvestrini y Guillermo Scherping por la ayuda prestada en la elaboración de este trabajo. 
ples frenos a la gestión de las municipalidades y a la de los directores de las escuelas.

Palabras clave: regulación de la educación; educación pública; gestión educacional; calidad de la educación.

Recibido y aceptado: junio 2010.

\section{Introducción}

Hace un tiempo se me preguntó quién está a cargo de la gestión de la educación pública escolar, de acuerdo a la regulación jurídica chilena. La responsabilidad por la educación pública escolar suele entenderse distribuida entre el gobierno central, que a través del Ministerio de Educación entrega financiamiento y define los contenidos mínimos para la educación escolar, y las municipalidades de las comunas donde se encuentran las escuelas, a cargo de la administración de sus recursos y en general de su gestión. Por eso se suele decir que la educación pública escolar es "municipal".

Ahora bien, ¿cómo la ley y otras normas estatales definen los poderes de gestión a nivel municipal? Según varios expertos en educación, de una manera "restrictiva", y, por eso, inadecuadamente. Elacqua, González y Pacheco (2008: 138) señalan que "La normativa que regula el sistema público de educación es inadecuada y crecientemente restrictiva en términos de gestión, lo que desincentiva el desarrollo de prácticas que aprovechen de mejor forma los recursos disponibles y que potencien un mejoramiento de la calidad de los aprendizajes impartidos". Asimismo, Raczynski y Salinas (2008: 112) afirman que "el marco normativo que regula el funcionamiento del sistema educativo [...] es inadecuado y restrictivo para una gestión eficiente de los recursos y no conduce a prácticas de aprendizaje. Aunque no el único", agregan, "el estatuto docente es el componente más mencionado y criticado en relación al marco normativo".

En éstos y otros estudios, sin embargo, suele faltar una explicación más detallada de la regulación jurídica que afecta a la gestión. Dar un paso en esa dirección es el objetivo de este trabajo. El carácter "restrictivo" de la regulación de la gestión de la educación pública escolar se expresa, primero, en que produce difusión de competencias de decisión (y por tanto de responsabilidades) entre varios agentes públicos o 
privados respecto de materias clave de gestión, agentes entre los cuales están incluidas no sólo las municipalidades o los directores sino también profesores y apoderados; y segundo, en que respecto de muchos aspectos clave simplemente no permite a esos agentes tomar decisiones. Para decirlo de manera más general, este trabajo muestra que, respecto a varias materias importantes de la gestión educacional, tiene poco sentido decir que nuestro sistema educativo escolar es "municipal". A lo más puede decirse que es parcialmente municipal. Por "materias o aspectos clave" de la gestión me refiero al nombramiento, remoción y remuneraciones de profesionales de la educación, aquello que en el Estatuto Docente aparece relacionado con el "ámbito administrativo" de la gestión (art. 7 a); dejaré fuera la dimensión financiera, aunque por supuesto ésta es importante para la educación pública. Al hacer esto, además, me concentraré en los funcionarios "titulares", que según la ley deben conformar el $80 \%$ o más de los profesionales de la educación de una comuna.

Hoy es un lugar común hablar de la "crisis de la educación municipal" y de cómo ésta podría resolverse. El porcentaje de matriculados en las escuelas públicas ha bajado considerablemente desde su creación durante el régimen militar y ha sido absorbido por los colegios particulares subvencionados por el Estado. La calidad de la educación municipal es, de acuerdo a varios indicadores, más baja que la del sector particular-subvencionado y particular. Entre las reformas, el gobierno de la coalición de derecha Alianza por Chile ha impulsado la creación de "liceos de excelencia" como una manera de hacer frente a la crisis. Pero en el año 2008 el liceo de mayor prestigio a nivel nacional, el Instituto Nacional, fue objeto de una toma estudiantil que atrajo la atención de los medios y el público general. En esa ocasión fue posible observar no solamente problemas de infraestructura sino también de gestión educacional, tanto respecto a la entrega de educación como de resolución del conflicto que surgió entre alumnos, profesores y la dirección del Instituto. Además, el Presidente S. Piñera ha dicho que su gobierno pretende buscar "nuevos y mejores modelos para la educación municipal" y que es necesario fortalecer el "liderazgo de los directores"*. Más allá de si uno comparte o no estas medidas, la organización de la educación pública escolar es un tema que nuestro país necesita enfrentar.

* El gobierno envió al Congreso el 30 de noviembre de 2010 un proyecto de ley que aumenta las atribuciones de los directores de las escuelas. (N. del E.) 
El plan de este trabajo es simple. Me referiré a (1) la regulación del nombramiento de profesionales de la educación, (2) término de funciones, (3) remuneraciones, (4) un caso que ilustra la regulación, y luego (5) concluiré. Un par de aclaraciones sobre lo que sigue: no defenderé la idea de que la organización actual de la educación pública escolar o las reformas que se le proponen son adecuadas o inadecuadas. En parte lo aclaro porque voy a hablar de la regulación de la situación laboral de personas de carne y hueso, de profesores y directores de escuela, y esa regulación es bastante protectora de esas personas. Se trata de una materia evidentemente sensible y sería un error que los profesores y directores que pueden haber venido a escucharme pensaran que estoy formulándoles una crítica a ellos. Me interesa separar la pregunta de política educacional — ¿cómo se debería organizar la educación pública? - de una pregunta distinta, cómo está organizada la educación pública hoy. Pienso que un recuento de lo que tenemos es una condición necesaria y previa para un debate sobre reformas. Avanzar hacia un diagnóstico en el ámbito de la regulación jurídica es el objetivo de lo que sigue ${ }^{1}$.

\section{Nombramiento de profesionales de la educación}

A primera vista, la función que la ley le asigna al director es importante. Según el Estatuto Docente, ella consiste en "dirigir y liderar el proyecto educativo institucional [del establecimiento educacional]" (art. 7). De acuerdo a lo anterior, una cuota de responsabilidad importante en la gestión educacional recae en quien tiene poder para nombrar al director. Ya que se dice que la educación pública es "municipal", uno esperaría que la ley le entregara al municipio ese poder.

Sin embargo, según la ley cada municipalidad es sólo un actor más (aunque importante) en el proceso de nombramiento de los directores titulares. Los postulantes al cargo de director se someten a un

${ }^{1}$ A menos que se indique, todas las disposiciones legales citadas ("artículos") son del Estatuto Docente. El Estatuto Docente fue promulgado como Ley 19.070 el 27 de junio de 1991 (y publicado en el Diario Oficial el 1 de julio de 1991). Desde entonces, el Congreso le ha introducido algunas modificaciones. Aquí se considerará solamente el texto actualmente vigente (este trabajo fue terminado en mayo de 2010). Las citas de artículos del Decreto Supremo 453 de 1991, Aprueba Reglamento de la Ley No 19.070, y del Estatuto Docente de los Profesionales de la Educación irán acompañadas de la abreviatura "DS". 
concurso público. El concurso es administrado por un departamento de la municipalidad, el Departamento de Administración de Educación (DAE), que elabora las bases, llama a concurso y recibe los antecedentes (art. 33 y arts. 82 y 83 DS). Luego el DAE entrega los antecedentes a una comisión calificadora de concurso (art. 84 DS). La comisión está integrada por cinco personas: (1) el director del DAE, (2) un director de otro establecimiento educacional del municipio, elegido por sorteo, (3) un representante de los padres y apoderados del establecimiento, elegido por éstos, (4) un docente del establecimiento, elegido por sorteo y (5) un funcionario del Departamento Provincial de Educación, es decir, un representante del Ministerio de Educación, quien actúa como ministro de fe (art. 31 bis). Las comisiones asignan puntajes a los candidatos (art. 32) y adoptan sus decisiones por mayoría simple (art. 91 DS). En resumen, en esta primera etapa la decisión sobre quiénes podrían ocupar un cargo de director es tomada en igualdad de condiciones por representantes de la municipalidad, los directores, los profesores, los apoderados y el Ministerio de Educación.

En una segunda etapa, el alcalde nombra al director, pero la decisión previa de la comisión que falló el concurso limita fuertemente sus opciones. El alcalde debe nombrar a alguno de los dos candidatos que obtuvieron los más altos puntajes y si opta por el segundo lugar debe justificar por escrito su decisión (en una "resolución fundada") (arts. 32 y 33). Por lo tanto, la decisión más importante respecto a la selección de la persona que ocupará el puesto de director la toman las comisiones de concurso, donde la mayor influencia de la municipalidad es probable que la tenga sólo en 1/5 de los votos (a saber, en el representante de la DAE).

He dicho "es probable" porque más allá de la regulación legal hay factores externos que podrían aumentar la influencia del alcalde en las comisiones de concurso. Los docentes y directores que las integran podrían querer evitar conflictos con el municipio que afecte su posición respecto a las decisiones que éste tome, por ej., en materia del término de la relación laboral o la gestión dentro del establecimiento, aunque, como veremos en un momento, las facultades del municipio en estas materias son restringidas.

En la dirección contraria hay una consideración importante respecto al voto del representante de la municipalidad en las comisiones de concurso, i.e. el director del DAE. Nótese que si bien el alcalde de- 
signa al director del DAE, y por eso se asegura de cierta lealtad de parte de éste, lo hace a partir de una lista conformada por una comisión de concurso (integrada por "los tres funcionarios de mayor jerarquía de la municipalidad", art. 34 inc. $1^{\circ}$ ), y más importante, al director del DAE se le aplica el Estatuto en materia de remuneraciones y término del car$\mathrm{go}^{2}$. Un director del DAE "díscolo" podría actuar bajo el alero de esta regulación y votar en las comisiones respectivas contra la decisión de la municipalidad, aunque, claro, es probable que por razones en parte internas (como el hecho de que otros funcionarios de la municipalidad nombren al director del DAE) y en parte externas a la regulación, aquello no ocurra frecuentemente.

Veamos ahora cómo son nombrados los profesores titulares. Ya que la educación pública es "municipal", también se podría esperar que en esta materia las decisiones fueran tomadas por el municipio, o al menos por los directores que el sistema educativo público ha nombrado (aunque ya sabemos que en ese sistema la participación del municipio es reducida). Sin embargo, en esta materia la regulación es parecida a la del nombramiento de directores. Nuevamente, el DAE de cada municipio administra un concurso de antecedentes (art. 33). En este caso la comisión calificadora del concurso está formada por (1) el director del DAE, (2) el director del establecimiento para el cual se quiere nombrar un profesor y (3) un profesor "elegido por sorteo entre los pares de la especialidad de la vacante a llenar" (art. 31). La comisión debe asignar puntajes y tomar su decisión por simple mayoría (art. $91 \mathrm{DS}$ ). El alcalde realiza el nombramiento, pero a diferencia del caso del nombramiento de directores, está limitado totalmente por la decisión de la comisión: el alcalde debe nombrar al candidato calificado con mayor puntaje por ésta (art. 33). Así que ni el municipio ni el director pueden decidir por sí solos quiénes ocuparán los cargos de profesores titulares.

Se podría sugerir que el municipio y el director probablemente coincidirán en la persona que debe ser nombrada, pero nuevamente ello

${ }^{2}$ El Estatuto rige para "quienes ocupan cargos directivos y técnico-pedagógicos en los departamentos de administración de educación municipal que por su naturaleza requieran ser servidos por profesionales de la educación" (art. 1). El jefe del departamento de administración de educación municipal debe ser un "profesional de la educación" (art. 34 inc. 2). Por lo tanto, al jefe del DAE se le aplica el régimen de término del cargo y de remuneraciones examinados en las secciones 2 y 3 . 
no es algo que la regulación haga probable: los directores de escuela son nombrados por una comisión plural en la cual el municipio tiene un rol limitado, como vimos arriba, así que un director de escuela que participa de una comisión de concurso podría tener una visión sobre el proyecto educacional que lidera muy distinta de la visión del municipio. Y por cierto, la opinión del docente que participa en la comisión calificadora de profesores podría también ser muy distinta de la del municipio, o de la del director de su escuela. Es posible incluso que en el nombramiento de ese docente no hayan participado el director de escuela o el director del DAE que ahora participan con aquél en la comisión de concurso. Por lo tanto, es razonable decir que la ley establece una difusión de responsabilidades entre distintos funcionarios respecto del nombramiento de profesores, dejando a factores "externos" el peso de la creación de una posición consensuada sobre el destino de la educación "municipal". Por ejemplo, la capacidad de persuasión de cada uno de ellos o de amenaza en base a otras consideraciones.

Hay un poder de las municipalidades relacionado con los nombramientos de directores y docentes que resta considerar. La municipalidad debe fijar todos los años la "dotación docente", es decir "el número total de profesionales de la educación que sirven funciones de docencia, docencia directiva y técnico-pedagógica" en las escuelas de la comuna, "expresadas en horas cronológicas de trabajo semanales", como dice el Estatuto (art. 20). El plan tiene una duración anual y debe ser aprobado a más tardar en noviembre del año anterior al que empieza a regir. En la medida que establece vacantes, es la antesala a los llamados a concursos que ya hemos examinado. Aquí la municipalidad no necesita conseguir la aprobación, ni siquiera consultar, a los directores de las escuelas de su comuna. Sin embargo, sí debe comunicar su decisión al Ministerio de Educación (a través de uno de sus departamentos, el Departamento Provincial de Educación ${ }^{3}$ ). El ministerio puede “observar" la dotación que ha fijado la municipalidad por no respetar "la relación óptima" entre profesionales y horas de trabajo, y el número de alumnos y cursos, aunque sólo con el objetivo de disminuir la dotación docente. En caso de que el municipio no acepte la observación del ministerio, la cuestión debe ser resuelta por dos organismos del gobierno central, uno que es parte del Ministerio de Educación y otro del Ministerio del Interior (la

\footnotetext{
${ }^{3}$ Ver art. 16 de la Ley $N^{\circ} 18.856$.
} 
Subsecretaría de Educación y la de Desarrollo Regional) (art. 23). La decisión debe tomarse por "mayoría", así que el gobierno central puede imponerse a las municipalidades ${ }^{4}$.

Para resumir: la ley entrega el poder de nombrar directores de escuela y docentes titulares a distintos funcionarios públicos, e incluso a miembros de la sociedad civil, todos los cuales participan de las comisiones calificadoras de concurso. El papel de las municipalidades, aunque central en la administración del sistema de concursos, es limitado respecto a la decisión final. Si existe una actividad consensuada de estos actores, ello se debe a factores "externos" y no se sigue de la aplicación del Estatuto Docente. Tal vez el poder más importante de los municipios consiste en fijar la planta docente, aunque el Ministerio de Educación puede poner objeciones a ella. Y por cierto, los directores de escuela, los "líderes" de los proyectos educativos de los establecimientos, no tienen poder de decisión. En conclusión, caracterizar a la educación pública escolar como "municipal”, por el papel del municipio o del director del establecimiento, confunde: comprender adecuadamente el sistema público escolar supone reconocer que, respecto del sistema de nombramientos, es un sistema con responsabilidades difusas.

\section{Término del cargo de profesionales de la educación}

La decisión sobre quiénes deben ser nombrados en los cargos de directores y profesores está ligada a aquella sobre el término de cargos en la medida que esta última libera puestos. ¿Quién y cómo toma esta decisión? Respecto al término de las funciones de los profesionales de la educación vemos un fenómeno parecido al de los nombramientos, y un ingrediente adicional. Aquí consideraré dos aspectos: primero, el rol de los distintos actores de la educación pública respecto de la aplicación de esas causales; y segundo, las causales reconocidas legalmente para el término de funciones directivas o docentes.

El Estatuto Docente consagra en términos generales el derecho de los profesionales de la educación titulares "a la estabilidad en las horas y funciones" fijadas en el momento de su nombramiento (art. 36). Como consecuencia de ese derecho, establece una lista taxativa de causales de cesación en el cargo de acuerdo a las cuales es más difícil des-

\footnotetext{
${ }^{4}$ Sobre la dotación docente y la terminación del cargo de docente, ver infra sec-
} ción 2. 
pedir a un profesor de una escuela o a un director que a un trabajador al cual se le aplica el Código del Trabajo. Y quien sea que aplique estas causales, tiene poco margen de maniobra. Además, si se revisan las reglas que definen quién las aplica, veremos que en general el director de escuela no tiene poder de decisión y que el municipio comparte el poder de aplicarlas con otras personas u órganos estatales.

Revisaré tres conjuntos de causales cuya aplicación requiere interpretación y que por eso, se podría decir, dejan un margen para la gestión educacional ${ }^{5}$. Antes de hacerlo, una aclaración: el director, si bien tiene estabilidad en su cargo, cada cinco años debe participar de un nuevo concurso público si quiere seguir ocupándolo. En todo caso, si lo pierde o no postula, y hay vacantes en la dotación docente, tiene derecho a trabajar como integrante de ella sin necesidad de concursar (art. 32). Los otros profesionales de la educación no tienen necesidad de volver a concursar en ningún caso. Con esa salvedad, tanto a docentes como a directores titulares les son aplicables las causales de término del cargo que resumiré ahora, comparándolas con las del Código del Trabajo. Hago esta comparación porque es usual hacer este paralelo, aunque pocas veces se explique con detalle. En este trabajo me mantengo agnóstico respecto a la cuestión de si la terminación del cargo de los profesores y directores debe o no someterse a una regulación como la existente en la legislación laboral común.

(1) Para empezar, el Código del Trabajo contempla como causal "las necesidades de la empresa, establecimiento o servicio" y permite al empresario invocarla a propósito de "la racionalización o modernización de los [servicios], bajas en la productividad, cambios en las condiciones del mercado o de la economía" (art. 161). Esta causal es aplicada directamente por el empleador, es decir por el empresario, sin perjuicio de que el trabajador despedido injustificadamente pueda pedir a un juez laboral que examine la decisión y declare que tiene derecho a exigir indemnización por el despido.

\footnotetext{
${ }^{5}$ Hay causales que sólo menciono en esta nota al pie. Son aquellas equivalentes a las del Código del Trabajo cuya aplicación no exige ponderar las necesidades del proyecto educativo (es decir, no se relacionan con la gestión educacional como la entiendo en este trabajo): la renuncia (art. 72 a), obtención de jubilación, pensión o renta vitalicia de un régimen previsional, respecto al cargo de profesor (art. 72 e), y muerte (art. 72 f). Cfr. los arts. 159 $\mathrm{N}^{\circ} 2$ (renuncia del trabajador) y $\mathrm{N}^{\circ} 3$ (muerte del trabajador) del Código del Trabajo.
} 
El Estatuto Docente no tiene una causal que le entregue el mismo poder al director de escuela o al municipio. Lo más parecido es el poder para fijar la dotación docente en el Plan Anual de Desarrollo Educativo Municipal, en base al cual se puede suprimir horas de trabajo y, así, el número de docentes o personas con puestos directivos que trabajan en la comuna (art. 72 i). Pero, como vimos, los directores de las escuelas no tienen poder de decisión respecto de la dotación docente (sin perjuicio de que puedan ser consultados), pues la dotación la fija la municipalidad. Y si bien el municipio es quien formula el Plan, éste puede ser "observado" por el Ministerio de Educación, y eventualmente, en caso de conflicto entre la municipalidad y el ministerio, el conflicto puede ser "resuelto" con la intervención del Ministerio del Interior. Además, cuando se aplica esta causal respecto de profesionales concretos, existen normas adicionales para determinar qué docentes o directores dejarán de trabajar. El alcalde aplica la causal, pero la ley fija el siguiente orden de prelación: primero, a los profesionales "contratados"; segundo, a los titulares de 60 o más años (en el caso de las mujeres) y de 65 o más años (en el caso de los hombres); tercero, a quienes tengan "salud incompatible para el desempeño de la función" (y éstas son las personas que han presentado licencias por un total de seis meses en los últimos dos años, sin contar licencias por accidentes del trabajo, enfermedades profesionales o maternidad); cuarto, se ofrece la renuncia voluntaria a quienes tengan "evaluación inferior". Si en este último caso ningún profesional renuncia, entonces el alcalde tiene poder para decidir quién deja la dotación (art. 73). Así que si esta causal deje un margen para la gestión, es muy limitado y, en todo caso, no un poder del director y tampoco exclusivamente de la municipalidad. Es muy distinta de la causal de las "necesidades de la empresa", pese a que a primera vista se parezca.

Otra causal que a primera vista se parece a "las necesidades de la empresa" que contempla el Código del Trabajo, y que por eso podría servir de instrumento de gestión educacional, es el resultado insatisfactorio en la evaluación docente. Sin embargo, respecto a la evaluación de docentes, ni el director ni la municipalidad tienen un rol importante. La evaluación contemplada por la ley se somete a lineamientos del Ministerio de Educación. Además, es realizada por Comisiones Comunales de Evaluación Docente, cuyos integrantes son profesionales de la educación de establecimientos diferentes de aquel donde el evaluado (o 
el director) se desempeña (arts. 72 g, 70 inciso 7). Por último, esta causal es de aplicación lenta: no es posible que un evaluado deje su cargo, aunque obtenga malos resultados, antes de que pasen dos años desde la primera evaluación, el evaluado haya pasado por un "plan de superación profesional” y por un total de tres evaluaciones (art. 70). La excepción a lo anterior, cuya decisión depende exclusivamente del profesional evaluado, es el caso en que éste (o ésta) se encuentre cerca de su jubilación y renuncie voluntariamente: en ese caso se exime de la evaluación y deja la dotación docente (art. 70 inciso final, y 72 k). Pero nuevamente aquí la decisión no es del municipio ni del director.

La evaluación del director y otros funcionarios directivos (o técnico-pedagógicos) tiene algunas características especiales. Los criterios de evaluación son, por una parte, los objetivos "institucionales y educacionales del [mismo] establecimiento", y por otra, los "compromisos de gestión". Estos últimos, señala la ley, son "acordados" entre el director y el director del DAE de cada municipio, siguiendo "los estándares de desempeño de directores, definidos por el Ministerio de Educación" (art. 70 bis). La evaluación en base a esos criterios puede ser la antesala para que la municipalidad remueva a alguno de estos funcionarios, pero se necesita un quórum especial de $2 / 3$ de los miembros del Concejo Municipal para ello (art. 70 bis inc. final). Además, para llegar a esa situación se deben haber realizado dos evaluaciones insatisfactorias $y$, tras la primera, se deben haber establecido mecanismos de apoyo al establecimiento, acordados entre su director y el director del DAE.

(2) El Código del Trabajo contempla la causal de "falta de probidad" y "conducta inmoral" (art. $160 \mathrm{~N}^{\circ} 1$ ), que son también aplicables por el empleador. El Estatuto contempla esas mismas causales (art. 72 b). Estos términos son vagos. Calificar una acción como "inmoral" equivale a juzgar que, todas las cosas consideradas, la acción es incorrecta. En materia de gestión algunas de las cuestiones más relevantes, se podría decir, son si el docente o director actúa de acuerdo al proyecto educativo o si tiene las capacidades que quien aplica esta causal considera valiosas o necesarias para un adecuado desempeño profesional. La "falta de probidad" parece tener un alcance más restringido, pero también deja un margen importante de evaluación. Como sea, la interpretación del director no tiene importancia aquí, quien sólo le puede sugerir al alcalde que en su establecimiento un profesor se encuentra en estas 
situaciones de "falta de probidad" y "conducta inmoral". Y el municipio no puede actuar rápidamente ni por sí solo al aplicar esta causal, porque el Estatuto exige que estas causales sean "establecidas fehacientemente en un sumario". El alcalde debe nombrar un "fiscal", que debe ser un funcionario de la misma o mayor jerarquía que la persona que es objeto del sumario (un docente o director para el caso de sumario a docentes, otro director para el caso de sumario a directores) y trabajar en otro establecimiento de la comuna (art. 127 de la Ley 18.883 y art. 72 b). Tras la investigación, el fiscal propone al alcalde destituir o absolver al inculpado (art. 137 de la Ley 18.883). La decisión final es del alcalde (art. 138 de la Ley 18.883). En este caso tiene sentido hablar de un poder de gestión "municipal", aunque se trata de un poder disminuido, pues la aplicación de la causal no puede ser inmediata y el alcalde debe escuchar la opinión del docente o del director que actúa como fiscal.

(3) Por último, el Código del Trabajo reconoce el "incumplimiento grave de las obligaciones que impone el contrato" (art. 160 $\mathrm{N}^{\circ} 7$ ), la "no concurrencia del trabajador a sus labores sin causa justificada" (art. $160 \mathrm{~N}^{\circ} 3$ ) y el "abandono del trabajo por parte del trabajador" (art. $160 \mathrm{~N}^{\circ} 4$ ), entre otras similares. También éstas son aplicadas por el empleador.

El Estatuto Docente contiene una causal comparable con las recién nombradas, el "incumplimiento grave de las obligaciones" del profesor o director. La decisión de aplicarla no es del director, sino que del alcalde. Éste no necesita consultar a otro funcionario u órgano del Estado. Sin embargo, esta causal se aplica en casos extremos, como muestran los ejemplos entregados por la ley: "incumplimiento [del profesional] de sus obligaciones docentes conforme a los planes y programas de estudio que debe impartir, abandono injustificado del aula de clases o delegación de su trabajo profesional en otras personas"; "la no concurrencia del docente a sus labores en forma reiterada" e "impuntualidades reiteradas del docente" (art. 72 c). El Código del Trabajo tiene una regulación más detallada, según la cual basta con tres días de inasistencias en un mes, o dos días seguidos, o dos días lunes, para el término de la relación laboral (art. $160 \mathrm{~N}^{\circ}$ 3). Por último, nótese que los profesionales de la educación a los que se les ha aplicado esta causal pueden volver a concursar para ingresar al establecimiento en que trabajaban o a otro de la comuna (art. 72 inc. final). Un alcalde que ha 
expulsado a un profesor puede encontrarse con que las comisiones de concurso reincorporan al profesional pese a que ha incumplido gravemente sus obligaciones.

En resumen: varias de estas causales o maneras de poner fin al ejercicio de un cargo educacional contemplan casos extremos de los cuales debe hacerse cargo la gestión educacional. Mediante otros instrumentos para poner fin a la relación laboral el alcalde tiene mayor ámbito de decisión (la dotación docente y la "conducta inmoral"), pero no son decisiones exclusivas del municipio: pueden ser objetadas por el ministerio (en el caso de la dotación), o requieren la opinión previa de otro docente o director (el fiscal del sumario por conducta inmoral). En ese sentido, la regulación es restrictiva porque limita las causales de despido ( si se las comparan con las del ordenamiento aplicable a los profesionales de la educación regidos por el Código del Trabajo) y porque difumina las responsabilidades acerca de la aplicación de causales que, a primera vista, entregan capacidad de maniobra a quien las aplica. Éste es un sistema de gestión que difícilmente puede ser llamado "municipal".

\section{Remuneraciones de profesionales de la educación}

Sobre las remuneraciones seré muy breve. El director de una escuela podría querer alterar el régimen de remuneraciones con el objetivo de influir en las conductas del equipo de profesionales. La municipalidad podría buscar lo mismo, respecto de los docentes o del mismo director. ¿Pueden hacerlo? En términos generales, la respuesta es negativa. Sólo en casos especiales la municipalidad tiene poder de decisión o influencia en una parte mínima de la remuneración, y en cuanto a uno de ellos la decisión final es del ministerio.

El Estatuto Docente fija gran parte de la estructura de remuneraciones de los profesionales de la educación, al proveer una remuneración básica mínima nacional (art. 35) y reglas formales para los pagos que excedan la remuneración base (arts. 47 a 67). Aquí el director o el municipio no tienen capacidad de maniobra,

Hay sólo dos pagos adicionales a la remuneración básica para los cuales la ley define solamente un rango dentro del cual debe definirse el monto a pagar y otros estándares para determinar el monto aplicado, en los cuales la municipalidad tiene cierta responsabilidad. La "asignación 
por responsabilidad directiva y técnico-pedagógica" alcanza hasta un $25 \%$ o $20 \%$ (según se trate de un director u otros cargos directivos respectivamente) de la remuneración básica, porcentaje que es definido por el DAE de cada municipio (art. 51) ${ }^{6}$. Además, la "asignación por desempeño en condiciones difíciles" alcanza hasta el 30\% de la remuneración básica mínima nacional. Sin embargo, nótese que en este caso al DAE le corresponde solamente "proponer" al Ministerio de Educación cuáles son los establecimientos que dan derecho a esta asignación por desempeño difícil, cuestión que éste debe definir mediante "un reglamento" (es decir, un decreto ministerial) (art. 50) ${ }^{7}$. Nuevamente, el carácter "municipal" de la educación es puesto en duda.

\section{Una ilustración}

Veamos un caso para ilustrar la aplicación de algunas de las reglas que hasta ahora he examinado. Como recordé al inicio de esta exposición, en el año 2008 la así llamada "crisis del Instituto Nacional" acaparó parte de la agenda noticiosa de los medios de comunicación nacionales. Varias tomas estudiantiles alteraron el funcionamiento normal del Instituto. Su comunidad discutió sobre las fuertes deficiencias que, según la opinión de varios actores del proceso, tenía su dirección y en general el establecimiento educacional. El DAE de la municipalidad de Santiago ordenó un sumario administrativo al equipo directivo del Instituto. Uno de los hitos finales de la crisis ocurrió cuando parte de ese equipo, incluido el rector, renunció en medio del sumario. En definitiva, el sumario administrativo concluyó que estas personas debían ser absueltas de los cargos formulados.

Algo que se puso a prueba en este proceso fueron las capacidades de gestión de las autoridades del Instituto y del municipio de Santiago, es decir, de quienes supuestamente son responsables de la gestión educacional. Dos ejemplos lo muestran.

(1) Uno se relaciona con el sistema de nombramiento de docentes. Una de las cuestiones discutidas durante la toma, y por las cuales se

${ }^{6}$ También se contempla hasta el $15 \%$ de la remuneración básica para "otro personal de las unidades técnico-pedagógicas".

${ }^{7}$ Más sobre las asignaciones de remuneraciones y los montos recibidos por los profesores en la década de los 90, en Mizala y Romaguera (2003), pp. 527-528, 535-538. 
formularon cargos al rector, fue la falta de profesores de algunas asignaturas y las alteraciones en los horarios de los profesores ${ }^{8}$. En sus descargos, el ex rector dijo que en los primeros días del año escolar 2008 renunciaron cinco profesores y otros cinco pidieron permisos administrativos; un mes después se acogieron a retiro voluntario y jubilación diez profesores, y un profesor presentó licencias médicas consecutivas, y luego agregó un dato interesante respecto de este complejo escenario. El ex rector sostuvo: "debido a la lamentable burocracia administrativa, sólo con fecha 2 de mayo se resolvió el concurso público de 10 cargos de 30 horas para diversas asignaturas, concurso que debió ser resuelto, como en años anteriores, en el mes de febrero, para así incluir al nuevo cuerpo docente en la determinación del horario"9. El rector se refería al concurso público para elegir profesores liderados por las Comisiones Calificadoras de Concurso. En este caso, el mecanismo de nombramiento de profesores titulares, al estar removidas de sus atribuciones y depender de decisiones externas (el DAE y otros profesores) parece haber contribuido a profundizar la desorganización técnico-pedagógica del Instituto.

(2) El segundo ejemplo se refiere a las reglas sobre el término de funciones del director. Varios representantes de profesores, estudiantes y apoderados del Instituto crearon en julio de 2008 una Mesa de Trabajo que produjo un informe. En el informe, además de diagnosticar los problemas del establecimiento educacional, la Mesa de Trabajo pidió al DAE de la Municipalidad de Santiago "su intervención inmediata en la administración y dirección del Instituto Nacional, alejando de su cargo"

8 "Informe Mesa de Trabajo Claustro Instituto Nacional", Santiago, 17 de julio de 2008, pp. 3-4, en Documentos de Sumario Administrativo contra Dirección de Instituto Nacional ("se ha producido una carencia en la disponibilidad de Profesores de Matemática, lo que se ha traducido en que varios cursos no han podido cumplir con su Plan de estudios [...] Es costumbre que los horarios sean modificados arbitrariamente hasta 6 [seis] veces en el año y en muchos casos perjudicando al profesor que por estos cambios horarios pierde la continuidad en el desarrollo del proceso educativo."). Fiscal Jorge Marticorena, "Escrito que declara cerrado el sumario y formula cargos", Santiago, 29 de septiembre de 2008, en Documentos de Sumario Administrativo contra Dirección de Instituto Nacional (cargo $\mathrm{N}^{\circ}$ 4: "Decidir e implementar un sistema de confección de horario de clases para el año escolar 2008 [...] que no ha logrado resolver la confección de un horario pedagógica y administrativamente bien estructurado").

${ }^{9}$ Omar Letelier, "Escrito de descargos a la acusación", s/f, en Documentos de Sumario Administrativo contra Dirección de Instituto Nacional, p. 12. 
al rector y su equipo directivo ${ }^{10}$. Tal vez ésta era la decisión más sensata considerando las tensiones acumuladas durante la toma y los problemas reales del establecimiento. Pero a la luz de las reglas que hemos visto, era algo que la municipalidad no podía hacer, aunque considerara que el equipo directivo había actuado incorrectamente. No es extraño que el DAE haya reaccionado ordenando solamente un sumario por "conducta inmoral" y rechazado la petición de remover o suspender al rector y su equipo. Es el único poder de gestión que la ley le entrega para casos como éste.

\section{Conclusión}

Según la legislación chilena, las municipalidades tienen una participación menor en el nombramiento de los directores de escuela. Cada municipalidad administra un sistema de concursos públicos, pero éstos son fallados por comisiones compuestas por representantes de los municipios, directores, profesores, padres y apoderados y del Ministerio de Educación. Respecto al nombramiento de profesores, también existen comisiones, con representantes del municipio, el director de la escuela y los profesores. Estas comisiones tienen un papel determinante en la selección de candidatos, porque los puntajes que asignan vinculan al alcalde, parcial o totalmente según el tipo de nombramiento. Además, los municipios fijan todos los años la "dotación docente", es decir los profesores y directores (medidos en horas de trabajo) que requieren las escuelas de la comuna, pero su decisión puede ser "observada" por el Ministerio de Educación, y si el municipio no sigue la observación del gobierno central, el mecanismo de resolución de conflictos contemplado por la ley hace participar además al Ministerio del Interior (y el impasse se resuelve por "mayoría de votos"). Más que "municipalización”, las reglas sobre nombramiento difuminan las decisiones en la comunidad escolar, el municipio y el gobierno central.

Cuando un candidato a docente o director ha pasado exitosamente por esa estructura de nombramiento, entonces se le aplica una

10 "Informe Mesa de Trabajo Claustro Instituto Nacional", Santiago, 17 de julio de 2008, p. 14, en Documentos de Sumario Administrativo contra Dirección de Instituto Nacional ("Conclusiones, $\mathrm{N}^{\circ}$ 3. [...] exigir a la [sic] Dirección de Educación Municipal de la Ilustre Municipalidad de Santiago su intervención inmediata en la administración y dirección del Instituto Nacional, alejando de su cargo al Rector señor Omar Letelier Ramírez y a toda su plana directiva”.). 
legislación protectora de su cargo que señala que el término de sus funciones se produce solamente en situaciones gravísimas. Algunas de las cuales exigen un procedimiento especial de investigación ("sumario administrativo") que no es liderado por el municipio, que sólo ordena su realización, sino por otro docente o director de escuela. (Los directores deben someterse cada cinco años a un nuevo concurso, pero ello es sólo para mantenerse en el cargo: con independencia del resultado, se mantienen en la dotación docente de la comuna.) Además, la estructura de remuneraciones está casi totalmente fijada de forma detallada por la ley, y respecto de aquellas pocas remuneraciones donde la ley permite un campo de maniobra, su determinación la realiza el municipio con el Ministerio de Educación.

La regulación jurídica de la gestión escolar (contenida en el Estatuto Docente y en otras leyes) suele entenderse como portadora de la "municipalización" de la educación pública, pero eso es un error. Esta regulación establece una difusión de competencias de decisión (y por tanto, de responsabilidades) entre varios agentes públicos o privados, dentro de lo cual se incluyen no solamente las municipalidades o los directores de escuelas, sino también profesores, apoderados y el Ministerio de Educación. Y en varios aspectos que algunos considerarían claves para la gestión, la regulación simplemente pone múltiples frenos a las intenciones de las municipalidades y directores de escuela.

\section{BiBLIOGRAFÍA}

Elacqua, Gregory, Soledad González y Paula Pacheco (2008). "Alternativas Institucionales para Fortalecer la Educación Pública Municipal”. En Cristián Bellei, Daniel Contreras y Juan Pablo Valenzuela (eds.), La Agenda Pendiente en Educación. Profesores, Administradores y Recursos: Propuestas para la Nueva Arquitectura de la Educación Chilena. Santiago: Universidad de Chile-UNICEF, pp. 134-153.

Raczynski, Dagmar y Daniel Salinas (2008). "Fortalecer la Educación Municipal: Evidencia Empírica, Reflexiones y Líneas de Propuesta”. En Cristián Bellei, Daniel Contreras y Juan Pablo Valenzuela (eds.), La Agenda Pendiente en Educación. Profesores, Administradores y Recursos: Propuestas para la Nueva Arquitectura de la Educación Chilena. Santiago: Universidad de Chile-UNICEF, pp. 105-132.

Mizala, Alejandra y Pilar Romaguera (2003). "Regulación, Incentivos y Remuneraciones de los Profesores en Chile". En Políticas Educacionales en el Cambio de Siglo. La Reforma del Sistema Escolar de Chile. Santiago: Editorial Universitaria, pp. 519558 . 